\title{
Analysis of the Reasons for the Left-Behind of the Elderly in Central and Eastern China
}

\author{
Ningning Zhang \\ School of Social Development, Nanjing Normal University, Nanjing, China \\ Email: baoding24@sina.com
}

How to cite this paper: Zhang, N.N. (2019) Analysis of the Reasons for the Left-Behind of the Elderly in Central and Eastern China. Open Journal of Social Sciences, 7, 275-286.

https://doi.org/10.4236/jss.2019.78019

Received: July 25, 2019

Accepted: August 20, 2019

Published: August 23, 2019

Copyright $\odot 2019$ by author(s) and Scientific Research Publishing Inc. This work is licensed under the Creative Commons Attribution International License (CC BY 4.0).

http://creativecommons.org/licenses/by/4.0/

\begin{abstract}
Based on Pierre Bourdieu's cultural capital theory and through field interviews, this paper extracts the daily spoken language of the left-behind elderly in the two places and analyzes the differences of left-behind causes in the central and eastern regions. Habituation means that the old people are already familiar with the production mode, life style and communication mode, and find their own class position in the mechanism of continuous operation. Old people from both places consider they stay in their homeland voluntarily, but there are some differences between them. The east is more like the bonds of nostalgia, while the middle is more like a realistic compromise.
\end{abstract}

\section{Keywords}

Left-Behind Elderly, Reasons for Staying behind, Habituation

\section{Introduction}

The old blue book: China's urban and rural elderly living conditions survey (2018) mentioned in "creating the atmosphere of respecting for the old age society life, maintaining the old social participation rights, respecting for the elderly society participation willingness to reflect the elderly life value. Provide opportunities for the elderly to show themselves, to participate in society, so that the elderly have a dignified life, a meaningful life." The left-behind of the elderly is common at present, and the reasons for left-behind are different from each other. It is worth pondering and discussing how the differences and commonness of the elderly in the eastern and central regions can be expressed behind these reasons.

\section{Literature Review}

"Left-behind old people are the old people over 60 years old (or over 65 years 
old)." [1] who stay in their hometown when their children go out [2]. Therefore, this paper tries to prove that there may be multiple reasons for rural elderly people to choose to stay behind in the mountains from different regions.

\subsection{Literature Review Abroad}

Due to the relatively perfect social welfare system in western developed countries, the elderly mainly rely on formal social support systems such as pension and endowment insurance. Although left-behind elderly phenomenon is common, their children go out to the family pension will not significantly impact, so the old problem of research about these countries focus more on how to improve the social service system, and combined with city and rural migration research is not much, for staying the analysis of the reasons is not involved. Foreign scholars' discussions on left-behind elderly mainly focus on three aspects: economic support, daily care and spiritual comfort. Left-behind elderly are more of a localized phenomenon in China, which is related to China's national conditions.

Foreign scholars have tended to improve the research on the elderly, focusing on the establishment and improvement of the pension service system, mainly aimed at solving the actual problems of the elderly, not just the analysis of the status quo and causes. For example, the "one gang one" model of college students and the elderly in Germany not only solves the problem of student accommodation, but also reduces the emptiness and loneliness of the elderly. In Japan, the industry of old-age care has been industrialized, a systematic old-age care service industry has been established, and the investment in old-age care service resources has been increased, which has solved many problems of left-behind elderly [3].

\subsection{Domestic Literature Review}

At present, most domestic researches focus on the social reasons for the formation of left-behind elderly. On the one hand, the development of urbanization and industrialization leads to the transfer of rural surplus labor to cities, and the young and middle-aged people who are the main rural labor force are transferred out, which leads to the "empty nest" of rural families and the "empty nest" of rural society."Industrialization acts as a magnet to attract rural "young adults" to the industrial sector, leaving the rural elderly, the sick and the disabled". [4] the loss of young adults' resources is an important reason for the left-behind of the elderly. On the other hand from the dual economic structure of China's urban and rural segmentation society the institutional background, "Without same city's social security and welfare benefits, the household registration system, and many other constraints, the rural-urban migrant workers can only be back and forth between city and rural, and families cannot be moved to the city, which leads to the emergence of left-behind elderly" [5].

There are social reasons, but also personal ones. Starting from the factors and characteristics of the elderly, a few researchers believe that "old people's nostalgia for the living environment, good relationship network and old people's sense 
of rejection of urban life and other factors" promote the selection of left-behind behaviors of the elderly. "[5] It's more the elderly who don't want to leave their long-term areas of residence, especially those over the age of 70, who have a distinct sense of rejection of urban life. The familiar lifestyle is an important reason for the elderly to stick to the countryside." [6]. Old people have formed certain habits in their hometown and have a good life network. Although the children want the elderly to live with them in the city, the living environment in the city makes the elderly choose to stay in their hometown. Zhou fulin considered the rural elderly lifestyle, communication style on the impact of left-behind. $\mathrm{Hu}$ qiangqiang also mentioned the familiarity with the original lifestyle. "due to the unsynchronization of migration time between children and the elderly, and the nostalgia of a large number of the elderly for their original residence, the carrier and object of supporting the elderly have undergone great changes in time and space during the urbanization process." [7].

Based on the above-mentioned domestic literature research, the author finds that there are two different views on the analysis of the reasons for the left-behind in the academic circle. At present, the reasons for the active left-behind gather in the familiar living environment and long-term stable communication mode, but nowadays the academic circle rarely interprets this special phenomenon from the perspective of economy and culture. Based on the theory, the author tries to assume that the old people choose to stay behind can also be explored from the mode of production. The traditional and original mode of production also exerts an important influence on the old people subtly, leading to the decision of rural old people to stay behind. In the literature of the present academic circle, what is truly local and reasonable with the theory is that wu fei's "living" absorbs the achievements of the western suicide theory, and liu yanwu's "BengTou" absorbs the development path of the Confucian tradition, and distill the three aspects of end-result, family unity and life. [8] therefore, the author tries to analyze and study the "habit-use" of the elderly from the aspects of lifestyle, production mode and communication mode from the literature and cultural capital theory of active left-behind.

\section{Research Design and Method}

\subsection{Research Objects}

In this paper, the elderly living alone or with their spouses and over 60 years old (including 60 years old) in Dong village (in the east region) and Qiaokou villages (in central region) were selected for field interviews. A total of 336 households were visited, among which 49 elderly households were deeply interviewed. Due to the one-week summer practice in both places in the early stage, the author has a better understanding of the situation of the two places. One is the hometown of the author, and the other is the hometown of the author's friend. Therefore, it is easier to conduct household survey, and the data obtained are true and effective. 
East village, one of the survey sites, is located in the west of Wangtan town, Keqiao district, ShaoXing city, ZheJiang province. It is 35 kilometers away from the urban area and located in the upstream of the xiaoshun river with beautiful scenery. The total number of households in the east village is 323 , with a total population of 1,026,212 of whom are above the age of 60 . With abundant forest resources, quiet environment and fresh air, east village is carrying out new rural construction. Most of the left behind old people on the mountain, while the village is close to the national road line, the traffic is convenient.

Qiaokou village, as another research site in central China, is located in zhaozhuyuan town, jinzhai city, Anhui province. Currently, there are more than 1850 people in the total population, more than 320 of whom are over 60 years old, accounting for $17.3 \%$ of the total population. Qiaokou village is located in the DaBie mountain, which is a typical case of the elderly left behind in the mountains.

\subsection{Investigation and Research Methods and Explanations}

This study mainly discusses the analysis of the reasons why the elderly choose to stay behind in the two places. Meanwhile, it also shows the living conditions of the elderly in the two places, and measures the reasons why the elderly choose to stay behind in the two areas from three dimensions of economy, culture and system.

The economy is mainly measured by three indicators: the disposable income of the elderly, the disposable income of the elderly's family, and the economic situation of the village where the elderly live. The author tries to assess the impact of economic factors on the left-behind situation by understanding the economic conditions in the eastern and central regions, and to assess the attractiveness of rural left-behind from the perspective of production modes.

The second dimension is culture, which means the traditional culture of the region and the attraction of the acquaintance society to the elderly should be evaluated. The communication and lifestyle of the countryside should be interviewed and investigated, including the comparison of cities. At the cultural level, it mainly involves the psychological level of the elderly, and explores their dependence on traditional culture in the eastern and central regions.

Finally, the reason why the elderly choose to stay behind is explained from the system level. The first indicator is the land system, that is, whether the local land system is reasonable and meets the requirements of the elderly so that the elderly choose to stay. The second indicator is the local social security system, to understand the difference of this factor in the two places and its different influences on the two places. The third indicator is the operating system. After understanding, the members found that the elderly in the two regions will grow tea and make tea as the main industry. Understand the similarities and differences of the management system in the two regions, so as to find the same and difference about stay behind. 
In the investigation, the author found that the old people in both places tried to use the slang "habituation" to express the reason why they live in the countryside. The author tried to analyze this expression of the old people from the perspective of rational choice and interpret their left-behind behaviors based on Pierre Bourdieu's capital theory.

\section{The Common Analysis of Left-Behind in the Central and Eastern Regions}

In the east village and Qiaokou village visits, there were similarities. The elderly said they wanted to stay in the countryside and expressed their ideas by saying they were "used to living"."Habituation" not only conveys the rational choice of the elderly, but also includes the traditional production mode, stable communication mode and capital flow under the familiar lifestyle in the whole countryside. The author tries to analyze the three aspects:

\subsection{Rational Choice behind Traditional Production Relations}

During the interview, the author found that the old people in the mountains were very familiar with the farming activities they lived in, and they had been familiar with and remembered this traditional and primitive farming method in the long-term field life. Personal disposable income is not high, while children disposable income is considerable, the elderly generally believe that children and themselves are not a family with independently family funds. The disposable income of the elderly depends on the subsistence crops grown in the mountains.

MouYong (Dong village in eastern China) as the eldest son in the family, he said that he could He raises chickens, harvests rice and plants vegetables

Sun shuiyuan (Dong village in eastern China) said "I don't have a lot of money in hand at ordinary times, and earn my income mainly by growing crops. Although I could earn a lot of money in the city, I tend to live in rural where I didn't need to waste many money. Of course, children usually give some money to me every month."

Compared with urban people, old people have little disposable income and low consumption expenditure. However, despite the inferior production environment, old people are not dissatisfied with the original production mode and find their survival value in it.

Wang shaoming (Qiaokou village in central China), he mentioned that "I can't do anything except growing land. What can I grow vegetables in the mountains (mountains)? It tastes good and is very interesting.

"It feels like you can't do anything in the city," says Shuilin (Dong village in eastern China). "but in the countryside you can find something to do."

"The village old people live on this land for many years. For them, this land is not only a means of making a living, but more like an 'old man'. They have a 'deep love' for the land where they are raised." [9] They like to pay their own sweat in nature to harvest the sense of belonging and value. Old man is engaged 
in the production process for the fields produced a kind of attachment, they found themselves in the field of their own belonging and value.

Wang Shaohuan (Qiaokou village in central China) when asked about his usual source of income, he replied, they make money by gathering tea and raising silkworms, which are self-sufficient.

This traditional mode of production not only gives them spiritual satisfaction, but also gives them a rational choice after weighing advantages and disadvantages. Bourdieu believed that "capital is accumulated labor, which can be occupied by actors or small groups of actors on the basis of social resources on an exclusive basis. It is a power written in the structure of objects or subjects, and it requires people to spend time to accumulate." [10].

The old man has spent decades in the rural areas, in which to build its own network of capital, they have the advantage in dealing with framing, can clearly understand temperament and preferences of the land, while they are at a disadvantage in the city. They don't understand the cold monster city. From this point of view, under the influence of the traditional mode of production, it is a kind of rational choice for them to choose their more lucrative field.

\subsection{Social Capital Accumulated in a Stable Way of Communication}

Social capital refers to when a person has some kind of persistent network of relationships, this network of people who are familiar with each other means that he actually or potentially has resources. The amount of social capital depends on the scale of the network of relationships that individuals can mobilize, and the amount of economic, cultural and symbolic capital owned by the various people connected by the network. In fact, there is also the flow of social capital in the process of rural communication. In the rural stable relationship, the old people have accumulated their own relationship network.

Shui lin (Dong village in eastern China), 80 years old, the eldest son of the family, assumed a lot of family responsibilities. When he was young, he was a village accountant and good at writing calligraphy with a high status in the village. He lives alone in the mountains, When needed some help, he always received some warm helps from his neighbors. He said that people were very cold in city. There was little communication between each other, there was no such thing as visiting neighbors, only he can do just watch TV at home, which was very frustrating.

The individual is a social being. No one can be truly "independent" without social connections. As the relationship between old man and the child becomes weak, at this time due to the principle of "compensation", the old man will choose a more familiar relationship to make up for the factor of female die and appear emotional "holes". There are more attractive in the countryside because of decades of old neighbors, while cities for them is "mirage" without the original accumulation of social capital. The completely unfamiliar environment in city makes old man feel scared. 
Shao huan (Qiaokou village in central China) said neighbors are like family members. They help each other when they need help. At a neighbor's wedding, he would take out the red envelope and drink the wedding wine.

In the rural social environment, the elderly have invested time, money and manpower, and gradually established their own social network and social resources in this stable relationship, which making their life more convenient and fulfilling. Like the old people in Dong village and in Qiaokou village have been living in the countryside for many years. In the long-term capital accumulation process, they adapt to the rural life and can effectively use their social capital to carry out various social activities. This stable communication mode is also a major reason for them to stay in the countryside.

\subsection{Emotional Support under the Familiar Lifestyle}

Fei Xiao tong mentioned that "local society in the local restrictions became born in this, grow in this society... It's a familiar society, a society without strangers... They are "familiar" with things as well as with people [9]. With the growth of age, the elderly become more attached to the living environment and lifestyle. Most old people choose to live alone in their old age, because they are unwilling to leave the social space where they have lived for a lifetime.

Zhong darong (Qiaokou village in central China) has heart disease, general physical condition. She said that she had been living in qiaokou village for more than 50 years since she got married in my twenties. She had been familiar with the way of life in this village, with its unique living habits. In winter, she just stay with old people in the village together in the sun, at an afternoon time may close her eyes to rest for a while, may chat for a while. Thus, it was a common phenomenon that group of old people moved position with the sun. Dairong mentioned that she did not like the apartment house in the city. Every day, the sunshine only lasts for a few minutes. After the sunshine leaves, she enters the room.

The social memory of the elderly runs through family life, social communication, cognitive activities and emotional experience, and is the cornerstone of building an environmentally friendly community with social care for the elderly. [11] the familiar rural lifestyle, the construction of public life space, mutual care between each other and the lifestyle of chatting together in the sunshine are what the old people want.

Dong mei (Dong village in eastern China), 75, with bad eyes, lost her husband and lived alone. The son worked in the city, the daughter was also very filial piety, often came back to see her. But she has been reluctant to go to the city, she said that the city didn't suit her. Dong mei mentioned that when she was in the countryside, she used to burn firewood to cook rice from a big pot. She was not afraid of too much rice. The leftover food could also be used for chickens, dogs, and cats.

Meanwhile, Xian min (Dong village in eastern China) is a typical village person who cannot adapt to the change of slippers in the apartment in the city. 
Old people always have more or less unaccustomed to city life, sometimes as small as a pair of slippers, a bundle of sunshine, a meal leftovers, time is in such an accumulation, little by little into a big gap. The elderly are accustomed to the rural lifestyle. For them, moving with the sun is a kind of comfort, not changing slippers is a kind of free and easy, not wasting a grain of rice is a kind of normality. However, everything changes in the city, and all the comforts become constraints.

In the process of both the old man's in-depth interviews, the two women are more sensitive to the old man's psychological. Rural elderly feel living in the city is not very convenient, the way of life is very different, between children and parents don't understand each other, pushing the old man's remaining options. The familiar life style includes the old people's attachment to the original place, the resistance to the city. Therefore, living in a more convenient and comfortable way is the rational choice of the old people in the real situation.

\section{The Difference Analysis of Left-Behind in Central and Eastern Regions}

The elderly in Dong village and Qiaokou village choose to stay in the countryside, which means that they stay there actively. However, there are some differences. In the materials of the field interview, the frequently used words for the reasons of staying behind in Dong village are "falling leaves return to their roots", while Qiaokou village says that there is a realistic compromise. These two words reflect the living status and life satisfaction of the elderly in different levels. It can be found that the left-behind elderly in the eastern region the bonds of nostalgia. In remote mountainous areas, they retain the original idea of relocating the land and returning to their roots. However, the elderly in the central region express a kind of compromise to the reality, which is a helpless choice in the real situation.

\subsection{The Bonds of Nostalgia in Eastern China}

The modern Chinese dictionary defines "nostalgia" as: "a feeling of deep longing for one's hometown. Nostalgia is an aesthetic state of mind when recalling the past rural life in urban space. It's a feeling of depression and loss, a form of nostalgia caused by missing hometown." [12] "nostalgia" involves space and place and is closely related to people's emotions [13]. Dong village was once the territory of Yue country. It has a stable life and pays attention to ethics.

\subsubsection{Nostalgia Is Root Which Never Be Broken}

Nostalgia is an important bond to maintain one's homeland. Returning to one's roots is the last watch for the elderly in their life journey. Nostalgia carries a lot, but it is more about the love of the native land and the most primitive root

Wang yougen (Dong village in eastern China) had lived in village for 65 years. In his early years, he went to work in the city. However, he was not accustomed to the city life. Living with sons is inconvenient, while living alone is freedom. 
The rural environment is good and the air is fresh. And here are used to living, also used to farming, The most important is that their roots are here. He said "when I was dead, I would buried, no one was buried outside in my village."

From the discourse of Wang yougen, we find that there are many factors influencing the elderly to stay in their native land, such as living freely, having a good environment and being accustomed to farming. However, the most frequently mentioned and emphasized is nostalgia."If our urbanization becomes a rural area we can't go back to and can't remember our nostalgia, it will undoubtedly be a rootless urbanization." [14].

The older generation stayed behind to maintain the destroyed roots of the city and to rebuild a traditional value concept. In the process of urbanization, a large number of young adults left the countryside, leaving only the elderly, who maintained their traditional roots in nostalgia.

\subsubsection{Nostalgia Is the Inheritance of the Family}

Shui lin (Dong village in eastern China) still retained a ding family tree. When Shui lin died, the family tree according to the generation by the family's second son, the 75-year-old Shui yuan inherited. Such as Shui yuan died by the family's third son Shuicheng custody, a family story in generations of inheritance.

This big family has deepened the memory and brand of this land through the inheritance of this genealogy. They all choose to return to their native land and find their own belonging.

The same situation happened in Cai youyuan's family (Dong village). At the age of 70, he lives in his main house, which is more than 300 years old. With the steady development of the family, the old people attach more importance to nostalgia and their hometown.

Through this traditional family tree, the Dong village strengthens the connection and prosperity of its clan. In this succession ceremony, the older generation also finds their own values and sense of belonging. The clan awareness strengthens the nostalgia of the older generation and their attachment to the land.

\subsubsection{Nostalgia Is for the Development of the City}

The elderly left behind in the countryside, which is also for their children left behind nostalgia. Children in urban development live a fast-paced life, so they need a harbor of soul and a place to slow down. At this time, hometown becomes a good destination. The nostalgia created by the old people in the eastern region also gives comfort to their children, so that they can return to their native land.

After ShuilLin (East village) died, the old house of ShuiLin family was abandoned. His children are all in town. His children said, "When father died, we would not often come back to the mountains, only in the Qing Ming festival." After ShuiLin's death, the children feel like they have no hometown, and the connection with their hometown becomes weak.

The central conference on urbanization proposed to "integrate cities into nature, so that residents can see mountains and water and remember their home- 
sickness". The old people in the east stay for their children, no matter how far they go, no matter how tired they are, at least they have a hometown to go back to. Therefore, the left-behind elderly in the eastern region maintain the fractured roots in a homesickness way. "Nostalgia" can be regarded as the root and source of Chinese culture. The central government has proposed that the development of urbanization should make residents "remember their nostalgia", which is an outstanding view in line with the world, a call to inherit traditional culture, and a warning to the Chinese nation to preserve roots and sources [15].

It doesn't matter where you live, what matters is whether you can feel your self-worth, have the lingering homesickness of settling down and giving it a sense of security, and have the self-esteem, self-confidence and pride that are neither self-abasement nor arrogant [16].

\subsection{Realistic Compromise in Central China}

In the previous article, the author put "Habituation" into operation. From the production mode, lifestyle and communication mode, it is concluded that the rural elderly in the eastern and central regions choose to stay behind with active meaning. At the same time from the economic, cultural and institutional perspective to analyze the reasons for left-behind. Dong village is obviously better than QiaoKou village in terms of the personal disposable income and household disposable income of the elderly. In terms of system, Dong village, located in ZheJiang province, has a relatively perfect guarantee system. Although QiaoKou village has recently tried "Photovoltaic Poverty Alleviation", there is still a gap in the middle. It can be found that the economic conditions in the eastern region are better, children generally in the urban development. The elderly in the central region are relatively backward economically and have inconvenient transportation. Most of their children work in other provinces. Therefore, the living pressure of the elderly in the central region is relatively heavy, presenting not poetic nostalgia, but a realistic helplessness.

Jinzhai county (Qiaokou village), a poor county in Anhui province, is a typical representative of left-behind phenomenon. The children of the left-behind elderly in Jinzhai county are far away from home. In interviews, the elderly show more realistic compromise. Their attachment to their homeland is much less than in the east.

Wang Shaohuan, (QiaoKou village in central China) 71, was dependent on his children and in average health. He is ZhongDaRong's husband. He mentioned he was nothing to the idea of falling leaves, he felt that "Anyway, people are old, and in their old age, they die. You don't know what it's like to go back to the roots, right? Die where you live, that's a habit. It is not convenient to speak elsewhere. We couldn't understand their speech. They don't understand us and they don't know us well."

From his words, the author found that he has seen the reality very thoroughly. His life without poetry and distance, he learned to compromise and see clearly in reality. As far as he was concerned, the so-called nostalgia and returning to the 
roots of fallen leaves was a kind of ethereal thing floating in the air. What he need to do is to step on every day.

Guo DiYing, 71, who lived near the ShaoHuan family. She was the poorest in the village. She still lived in the earth house with her grandchildren. Every day she lived strong, planting peanuts, peanuts. Her world is small and there is no such thing as nostalgia.

In the materials of the field interview, the frequently used words for the reasons of staying behind in Dong village are "falling leaves return to their roots", while Qiao kou village says that there is a realistic compromise. In this way, the phenomenon of different reasons for staying behind in different areas can be attributed to a variety of reasons. Firstly, it can be summarized as economic reasons. Compared with the central region, the eastern region develops faster, so its material conditions and living conditions are better. The second is the influence of the family. It is worth further exploration for the reasons why the eastern parents' words and deeds keep their children reminded of the importance of returning to their roots.

\section{Conclusion and Prospect}

This study shows that there are active left-behind phenomena in the central and eastern regions, rather than the passive left-behind phenomenon always mentioned by the academic circle. The two regions use the word "Habituation" to express left-behind. Dong village tends to be homesick for its hometown, while Qaokou village is more of a compromise for reality. These are just two cases in the central and eastern regions, which cannot explain the whole situation in the central and eastern regions, but partly show the psychological state and real needs of the elderly left behind in their respective regions. The research in this paper can better understand the inner world of the elderly and help them better adapt to the changes in the urbanization, so as to truly care about and help their elderly life.

\section{Conflicts of Interest}

The author declares no conflicts of interest regarding the publication of this paper.

\section{References}

[1] Zhou, F. (2006) Research on Left-Behind Elderly in China. Population of Northwest China, No. 1, 46-56.

[2] Du, P. and Yang, H. (2009) Approaching the Left-Behind Elderly in Rural Areas and Speaking for the Lonely Group on "Lonely Sunset-China's Left-Behind Elderly in Rural Areas". Journal of China Agricultural University (Social Science Edition), No. 2, 177-182.

[3] Kou, J. (2012) Ethical Principles of Caring for "Empty Nesters" in Vulnerable Groups. Journal of Hengyang Normal University, No. 4, 74-78.

[4] Dai, W.D. and Kong, Q.Y. (2005) Analysis of Dual Effects of Rural Labor Transfer 
Employment on Rural Pension Security-Based on the Investigation of Rural Labor Transfer Employment in Anhui Province. China Rural Economy, No. 1, 40-50.

[5] He, Z.C. and Ye, J.Z. (2009) Research Review on Left-Behind Elderly in Rural Areas. Journal of China Agricultural University (Social Science Edition), No. 6, 24-34.

[6] Wu, R.J. (2002) Study on the Care Problems of Rural Left-Behind Elderly in the Process of Population Urbanization. Population, No. 2, 43-46.

[7] Hu, Q.-Q. (2006) Rural "Left-Behind Elderly" Care in the Process of Urbanization. Journal of Nanjing Cadre Institute of Population Management, 22, 25-28.

[8] Liu, Y.W. (2014) On "Running Head"-Understanding a Local Concept of Farmer Suicide in Hebei Village. Sociological Review, 2, 68-86.

[9] Fei, X.T. (2012) Rural China. Peking University Press, Beijing.

[10] Bourdieu (1997) Cultural Capital and Social Alchemy. Shanghai People's Publishing House, Shanghai, 189-190.

[11] Chen, J. (2019) Changing Filial Piety: A Study on Living Memory and Social Care of Left-Behind Old People from the Perspective of Local Culture Revitalization-An Oral History Analysis Based on T Village in H Province. Lanzhou Journal, No. 6, 183-193.

[12] Chen, C. (2011) Contemporary Interpretation and Connotation Evolution of "Homesickness"-The Pursuit of Local Complex in Contemporary Chinese Literature. Research on Creation, Contemporary Literature, No. 2, 78-81.

[13] Zhang, X.D. (2014) Why It Is Important to Remember Homesickness. China Economic Report, No. 2, 26-30.

[14] Cheng, Z.F., Zhou, S.Y. and Zhang, B.X. (2015) Cultural Geography Perspective of the Study of "Homesickness". Journal of Beijing Union University (Humanities and Social Sciences Edition), 13, 64-70.

[15] Liu, Q. (2014) "Homesickness" Is Actually "City Sorrow". Beijing Daily, February 17.

[16] Yue, Y.Y. (2015) Homesickness and Folk Culture Theory of Urbanization. Folk Culture Forum, No. 2, 11-14. 